\title{
Real options analysis of investment in solar vs. wind energy: Diversification strategies under uncertain prices and costs
}

\author{
Ardjan Gazheli* \\ Institute for Environmental Science and Technology \\ Universitat Autònoma de Barcelona \\ Edifici Z - Campus UAB \\ 08193 Bellaterra \\ Spain \\ a.gazheli@gmail.com \\ and \\ Jeroen van den Bergh ${ }^{* *}$ \\ ICREA, Barcelona, Spain \\ \& Institute for Environmental Science and Technology \\ Universitat Autònoma de Barcelona \\ Edifici Z - Campus UAB \\ 08193 Bellaterra \\ Spain \\ jeroen.bergh@uab.es
}

February 2017

Published as:

Gazheli, A., and J. van den Bergh (2018). Real options analysis of investment in solar vs. wind energy: Diversification strategies under uncertain prices and costs. Renewable and Sustainable Energy Reviews 82(3): 2693-2704. https://doi.org/10.1016/j.rser.2017.09.096 


\begin{abstract}
:
In this paper we study a community or firm considering to diversify its investment in two distinct renewable energy technologies, namely wind and solar PV electricity. We assume technological learning curves as a function of cumulative capital investment. A real options approach is applied as it takes into account uncertainty about prices and learning, as well as irreversibility associated with investment decisions. We investigate three different cases, dealing with uncertainty about future electricity prices, and uncertainty about the speed with which learning drives the costs of wind and solar electricity down. We assess the minimum threshold for the stochastic price and the maximum electricity production cost that makes it optimal for the firm to invest in the two technologies. The results show the importance of the learning rate: it affects anticipation of the option to invest in, and reduces the critical threshold for exercising it, or for higher initial production cost. The greater the amount of capital invested, the more learning stimulates earlier exercising of the option to invest. The firm will then anticipate the option to invest and for lower critical threshold values if all capital is invested in one technology. If capital investment is diversified, then the option should be exercised at a higher a*. More uncertainty in energy prices or technology costs postpones the option to invest. In the case of more certain electricity prices due to price subsidies, governments implicitly protect investors against price fluctuations and uncertainty. Although investing in both solar and wind may be profitable under particular conditions of price and cost uncertainty, the theoretically optimal strategy is generally investing in only one technology, that is, solar or wind, depending on their relative initial costs and learning rates. This suggests that the practice in most countries of diversifying renewable energy may reflect a mistaken strategy.
\end{abstract}

Keywords: Investment, real options, renewable energy, sunk costs, uncertainty. 


\section{Introduction}

The energy sector is currently facing different challenges connected to, among others, climate change, strongly varying energy prices, peak oil and foreign dependence. For this reason, issues connected to energy are high at national, European and Global agendas. The easiest way to reason about these problems is by considering a most likely definite solution to the core problem, that is, the emission of greenhouse gases, notably carbon dioxide (van den Bergh, 2010). Given that nuclear power involves serious concern about calamity risks and long-term radioactive waste, renewable energy seems to offer the only definite solution. It can in principle support the supply of electricity and other types of energy carriers in a carbon-free way. Of course, this requires that renewable energy equipment, including all intermediate industrial and transport activities involved, are produced with renewable, carbon-free energy. In order to allow for a broad-scale adoption of renewable energy, it needs to produce electricity at marketcompetitive prices, possibly through price subsidies in the form of feed-in tariffs (Chen and Funke, 2015).

Renewable energy sources (RES) are considered to play a fundamental role in decreasing the above mention problems and creating new business opportunities. However, because of high initial costs of investments, low rates of return and uncertainty about future markets (competition, prices) and technological developments complicate firms' decisions on such investments (Menegaki, 2008; Muñoz et al., 2009). Within renewable energy, one can identify wind turbines, water power, biomass energy (including biofuels), concentrated (solar) heat power, and solar photovoltaics (PV) as the main candidates for future dominance. However, which technology will ultimately emerge as the most attractive is uncertain. These are different technologies, with distinct initial costs and learning curves. A community or investor may want to diversify the investment in such technologies as a response to any uncertainty about their future costs and learning curves.

Traditional evaluation models such as cost-benefit analysis, notably using the net present value (NPV) criterion, fail to assess the strategic dimension of investments in RES by leaving out risk and uncertainty associated with future rewards (Brealey and Myers, 2003). More sophisticated evaluation techniques are needed to deal with these. One is real options theory which sees the firm as an investor holding a financial option. It gives it the flexibility to exercise the option now or wait (at a cost) in order to acquire more information on uncertain market (competition and prices) and technological conditions. In line with investments in RES, the initial investment cost is considered irreversible, that is, once the firm decides to invest, it kills the option and the investment cost is considered sunk. The aim of this study is to develop a decisionmaking model considering the factors affecting firms' willingness to invest in renewable energy projects, such as wind or solar energy (see Table 4.2).

The problem we try to solve concerns the choice of a firm or community having to decide about how much to invest in two types of renewable energy technologies, namely wind and solar PV. The earnings from the two technologies are calculated as revenues minus costs (investment and maintenance costs). Revenues are obtained by selling the energy (electricity) produced with the two technologies (which is not storable) at a single market price. We consider three different cases with our model, motivated by the fact that one cannot solve the model for two learning curves (wind and solar) with both stochastic learning rates, or for one stochastic learning rate and a stochastic price. Even numerical analysis is difficult in these cases as no intermediate analytical solutions to work with are available. The three cases are: 1) a general case where the two technologies have different electricity production cost curves, with the solar technology starting at a higher initial cost than wind but showing a faster (steeper) learning 
curve and thus cost reduction rate; 2 ) a specific case where only the cost of solar PV electricity decreases over time according to a learning or experience curve, while the cost of electricity produced with wind technology is constant; 3 ) price as deterministic and the cost of the solar technology and its learning rate as stochastic. In the first two cases we consider uncertainty at the price level and solve the problem by finding the minimum price level and optimal timing, for which it is profitable for the firm to invest. We show the difference between the NPV method and the real option approach which takes into account important factors such as drift and uncertainty in the stochastic prices of electricity. In the third case, we investigate how the learning rate of solar PV and stochasticity of the cost of electricity production with this technology affect the decision to invest. We identify the maximum value in the production cost at which the firm is willing to invest a part of the capital in a determinate technology.

The reminder of the paper is organized as follows. Section 2 reviews the literature on applications of real options theory to investment in renewable energy. In Section 3 the basic setup for the model is presented, and general analytical results are derived. In Section 4 we offer numerical analysis of the three model cases. Section 5 concludes.

\section{Real options and renewable energy}

Investments are an important part of the continuity of a firm as bad investments taken in the present can lead to unsustainable situations in the future or even to the bankruptcy of the firm. That is why not only the intuition of good investments but also the method of evaluation acquires so much importance.

Investments share three important characteristics:

- The investment is partially or completely irreversible, meaning that the initial cost of the investment is partially or totally sunk and cannot be recovered.

- There is uncertainty connected to the future rewards of the investment. It is better to associate probabilities to the future cash flows.

- The time when to incur the investment is important. The investment decision can be postponed in order to have more information, however, this will not reduce completely uncertainty.

Traditional methods such as NPV or discounted cash flows (DCF) are used to evaluate investments. However, these methods are not very sophisticated dealing with complex investments such as those in RES for example. The DCF approach for example is not ideal since it bases its prediction on the certain future rewards the investment will generate thereby not considering important aspects such as risk and uncertainty. The NPV on the other hand considers the investment as a now or never option, thereby leaving out the important option to postpone or delay an investment for the sake of acquiring information or waiting to see how market conditions develop. In addition, these methods do not consider the irreversibility of the investment cost. As the firm undertakes the investment, it will not be able in the future to recover the initial investment cost if market conditions turn out to be not favorable anymore.

Irreversibility and the possibility of postponing the investment in time are two important characteristics of investments. Thereby, a firm with the option to invest is seen as holding an "option" which is similar to a financial option. In this case the firm has the right, but not the obligation to exercise such option. When the firm decides to exercise the option, it "kills" the option to invest giving up the possibility to wait for new information (or more results of learning, innovation) to arrive that may be of vital importance (Dixit and Pindyck, 1994). By taking such 
decision the firm makes an irreversible step as it cannot disinvest should the market conditions turned out bad. This lost option value is an opportunity cost that must be taken into account as part of the costs of the investment.

\subsection{A typology of real options}

Table 1 introduces the different types of real options, the definition and their possible application in renewable energy technologies. 


\begin{tabular}{|c|c|c|}
\hline Type & Definition & Renewable energy \\
\hline Defer option & $\begin{array}{l}\text { Gives to the holder the ability to wait to invest } \\
\text { the money. This means that the company has } \\
\text { the opportunity to invest now or wait and } \\
\text { acquire more information for future market } \\
\text { conditions. Such types of options are used for } \\
\text { the evaluation of investments in natural } \\
\text { resource extraction, real-estate development, } \\
\text { farming, etc. }\end{array}$ & $\begin{array}{l}\text { The firm having the option to build and } \\
\text { operate a PV power plant or wind turbine } \\
\text { can defer the construction until demand } \\
\text { and technology prices justify such } \\
\text { building. In renewable energy } \\
\text { technologies this is important looking at } \\
\text { the development of technologies. }\end{array}$ \\
\hline $\begin{array}{l}\text { Time-to-built } \\
\text { option }\end{array}$ & $\begin{array}{l}\text { Are used to evaluate project that require a } \\
\text { particular time for the construction or start-up } \\
\text { and such period is not covered by any profit. } \\
\text { This option gives to the holder the possibility to } \\
\text { abandon the project if market conditions turn } \\
\text { unfavorable. These types of options are } \\
\text { suitable to evaluate R\&D projects in } \\
\text { pharmaceutical companies and long- } \\
\text { development capital-intensive projects }\end{array}$ & $\begin{array}{l}\text { Construction of renewable power plants } \\
\text { can be developed in stages, thus allowing } \\
\text { a continuous review of demand trend, } \\
\text { price levels and technologies in order to } \\
\text { continue with the next stage or not. }\end{array}$ \\
\hline $\begin{array}{l}\text { Alter operating } \\
\text { scale option or the } \\
\text { option to expand } \\
\text { contract, shut } \\
\text { down and restart }\end{array}$ & $\begin{array}{l}\text { Are used to evaluate projects with the } \\
\text { possibility to expand and increase in scale if } \\
\text { market condition turns favorable (resource } \\
\text { extractions, construction, consumer goods). }\end{array}$ & $\begin{array}{l}\text { The scale of the investment is also } \\
\text { important. In favorable market } \\
\text { conditions a Wind plant can be extended } \\
\text { further, while if market conditions are not } \\
\text { favorable, then such plant can be } \\
\text { reduced. }\end{array}$ \\
\hline Abandon options & $\begin{array}{l}\text { Are important in the case when a firm sees that } \\
\text { market conditions are turning to be not } \\
\text { favorable. By using such an option, the firm can } \\
\text { see if and when it is possible to abandon a } \\
\text { project in order to organize a resale of the } \\
\text { capital equipment and not lose the whole } \\
\text { investment by just waiting (airlines, railroads). }\end{array}$ & $\begin{array}{l}\text { Renewable energy projects are very } \\
\text { dependent on changing regulations, } \\
\text { market conditions and technology. If for } \\
\text { example a technology becomes old, then } \\
\text { the firm has the option to abandon the } \\
\text { project and resume any residual value. }\end{array}$ \\
\hline Switch option & $\begin{array}{l}\text { Gives the firm the option to switch the inputs } \\
\text { or the outputs of their business. Having the } \\
\text { flexibility to switch from one product to the } \\
\text { other when the market conditions turn out to } \\
\text { be more favorable is important for the firm } \\
\text { survival. }\end{array}$ & $\begin{array}{l}\text { The option to switch represent a very } \\
\text { good tool for firms between different } \\
\text { uses of the land for example. An } \\
\text { agricultural firm can decide either to } \\
\text { continue agricultural production, or if } \\
\text { conditions turn out favorably switch to } \\
\text { energy production form PV or wind. }\end{array}$ \\
\hline Grow option & $\begin{array}{l}\text { Can be interpreted as the acquisition of a } \\
\text { capability that allows the firm to take a better } \\
\text { advantage of future growth opportunities }\end{array}$ & $\begin{array}{l}\text { This type of options is important in } \\
\text { renewable energy where we have seen a } \\
\text { continuous market deregulation lately. } \\
\text { Considering factors such as oil prices } \\
\text { shock and environmental concern, } \\
\text { renewable energy market can be } \\
\text { expected to expand rapidly. }\end{array}$ \\
\hline
\end{tabular}

\subsection{Real options theory applied to renewable energy investments}

The energy sector has seen a major transformation in the last years. It has passed from a regulated and state owned sector to a privatized and deregulated one. Currently there are a large number of companies operating in the market thereby introducing a large uncertainty and making the sector highly competitive. Another characteristic of investments in this sector is connected to the high initial costs of investments in these technologies and the irreversibility of such investments. These factors opened the door for the use of real options theory for the evaluation of investments in energy.

The application of the real options technique for the evaluation of investments in the energy sectors has some history. The first application was by Tourinho (1979). Later on, Brennan and Schawrtz (1985) applied the option pricing theory for the evaluation of irreversible natural 
resources in the Chilean copper mines. In the same years, the real options theory was used for the evaluation of investments in the oil industry (Siegel et al. 1987; Paddock et al., 1988; Ekern, 1988).

The decade 1990-2000 signed the golden decade for the development of the real options theory. In these years were accomplished the works from Dixit and Pindyck (1994), Trigeorgis (1996) and Amram and Kulatilaka (1999). These authors contributed on the publication of different books and papers further developing the real options theory and applying it to investment in different fields including the energy sector also.

The use of real options theory in the energy sector as a result of the continued deregulation is introduced also by Felder (1996). Following on this, Ghosh and Ramesh (1997) investigate the development of an options market for bulk power trading in a market setup while considering power system planning and operational constraints and/or requirements. In doing so they consider the different market based financial derivative instruments which can be used to trade electrical power in bulk and examines how established tools such as Optimal Power Flow (OPF) may be applied in helping to develop a price for bulk power transactions under a market based setup.

More recent is the use of the real options method for the evaluation of investments in renewable energy projects. Table 2 introduces some of the most important studies applying this technique, the types of uncertainties treated and the different tools used. 
Table 2 Real option studies of renewable energy (in chronological order)

\begin{tabular}{|c|c|c|c|c|c|c|}
\hline Authors & $\begin{array}{l}\text { Renewable } \\
\text { energy }\end{array}$ & Uncertainty & Tool & Year & $\begin{array}{l}\text { Theoretical } \\
\text { or applied }\end{array}$ & Region \\
\hline Hoff et al. & PV & Price & Tree & 2003 & $\begin{array}{l}\text { Applied: } \\
\text { Residential }\end{array}$ & $\begin{array}{l}\text { San Jose, } \\
\text { California }\end{array}$ \\
\hline Fleten and Maribu & Wind & Price & PDE & 2004 & Applied & $\begin{array}{l}\text { Data from Nord } \\
\text { Pool financial } \\
\text { market }\end{array}$ \\
\hline Wang and de Neufville & Hydro & Price & Tree and sim & 2004 & Applied & China \\
\hline Zhang et al. & Hydro & Water and price & Simulation & 2005 & Applied & Not specified \\
\hline Wang & Hydro & Price & Tree and sim & 2005 & Theoretical & $\begin{array}{l}\text { PhD } \\
\text { dissertation }\end{array}$ \\
\hline Hedman and Sheble & $\begin{array}{l}\text { Hydro and } \\
\text { wind }\end{array}$ & Wind & PDE and sim & 2006 & $\begin{array}{l}\text { Applied: } \\
\text { firm }\end{array}$ & Not specified \\
\hline Wang and Neufville & Hydro & Price & Tree and sim & 2006 & Applied & Not specified \\
\hline Yu et al. & Wind & $\begin{array}{ll}\text { Price and } \\
\text { demand }\end{array}$ & Sim & 2006 & Applied & Spain \\
\hline Zhou et al. & Wind & Price & Sim & 2007 & Applied & California \\
\hline Kjarland & Hydro & Price & PDE & 2007 & Applied & Norway \\
\hline Sarkis and Tamarkin & PV & $\begin{array}{l}\text { Technology and } \\
\text { policy }\end{array}$ & Tree & 2008 & & \\
\hline Dykes and de Neufville & Wind & Price and policy & Tree & 2008 & $\begin{array}{l}\text { Applied: } \\
\text { farm }\end{array}$ & Ohio \\
\hline Bockman et al. & Hydro & Price & PDE & 2008 & Applied & Norway \\
\hline Kimbaroglu et al. & $\begin{array}{l}\text { Renewable } \\
\text { power }\end{array}$ & Price & & 2008 & Applied & Turkey \\
\hline Kjaerland and Karlsen & $\begin{array}{l}\text { Hydro and } \\
\text { thermal }\end{array}$ & Water and costs & Sim & 2009 & Applied & Norway \\
\hline Scatasta and Mennel & Wind & $\begin{array}{ll}\begin{array}{l}\text { Policy and } \\
\text { revenues }\end{array} \\
\end{array}$ & PDE & 2009 & Applied & Germany \\
\hline Munoz et al. & Wind & Price & Tree and sim & 2009 & Applied & Spain \\
\hline Mendez et al. & Wind & Cash flows & Tree and sim & 2009 & Applied & East Europe \\
\hline Cheng et al. & Wind & $\begin{array}{l}\text { Price, cost and } \\
\text { policy }\end{array}$ & Tree & 2010 & Applied & 2 base cases \\
\hline Siddiqui and Fleten & $\begin{array}{l}\text { Renewable } \\
\text { energy }\end{array}$ & $\begin{array}{l}\text { Price and } \\
\text { technology }\end{array}$ & PDE & 2010 & Applied & Not specified \\
\hline Ashuri and Kashani & PV & $\begin{array}{l}\text { Technology and } \\
\text { price }\end{array}$ & Tree and sim & 2011 & & \\
\hline Martinez and Mutale & PV & $\begin{array}{l}\text { Demand } \\
\text { response }\end{array}$ & Tree and sim & 2011 & Applied & UK \\
\hline Martinez and Mutale & Hydro & Price & Tree and sim & 2011 & Applied & Not Specified \\
\hline Martinez and Mutale & Wind & Wind & Tree and sim & 2012 & Applied & US \\
\hline Martinez et al. & $\mathrm{PV}$ & Technology & Sim & 2012 & Applied & UK \\
\hline Lin and Wasseh & PV & Price & Tree & 2013 & Applied & China \\
\hline Gazheli and di Corato & $\mathrm{PV}$ & Price & PDE & 2013 & Applied & Italy \\
\hline Di Corato et al. & Biomass & Price & $\mathrm{PDE}$ & 2013 & Applied & Sweden \\
\hline De Olivera et al. & Biomass & Price & $\mathrm{PDE}$ & 2014 & Applied & Brasil \\
\hline Zhang et al. & PV & Price and cost & Tree & 2014 & Applied & China \\
\hline Kim et al. & Wind & Price & Tree & 2014 & Applied & Korea \\
\hline Monjas Barroso & Wind & $\begin{array}{l}\text { Price, cost, } \\
\text { technology }\end{array}$ & Sim & 2014 & Applied & Germany \\
\hline Kroniger and Madlener & Wind & Price and wind & PDE and sim & 2014 & Applied & Germany \\
\hline Santos et al. & Hydro & Price & Tree & 2014 & Applied & \\
\hline Jeon et al. & PV & $\begin{array}{l}\text { Energy and } \\
\text { environment }\end{array}$ & Sim & 2015 & Applied & Korea \\
\hline Biondi and Moretto & $\mathrm{PV}$ & Price and costs & PDE & 2015 & Applied & Italy \\
\hline Wasseh and Boqiang & $\begin{array}{l}\text { Renewable } \\
\text { power }\end{array}$ & $\begin{array}{l}\text { Price and } \\
\text { technology }\end{array}$ & Tree & 2015 & Applied & Liberia \\
\hline
\end{tabular}

Note: extension of overview in Martinez-Cesena et al. (2013). 
As shown in the table, these studies are mostly applied and are focuses on particular regions. The main objective of such studies is to provide tools in order to test the different climate or energy policies implemented by different countries.

\section{Model set-up}

Consider a firm or community that wants to diversify its investment in renewable energy by considering two options. In our particular case, we interpret the setting as the firm having to choose between investing in wind and solar PV energy. The earnings from the two technologies are calculated as revenues minus costs (investment and maintenance costs). Revenues are obtained by selling the energy (electricity) produced with the two technologies (which is not storable) at a single market price.

In Section 3.1, we consider the case of both technologies having different starting costs and different cost curves, with the solar technology starting at a higher initial cost than wind but showing a steeper learning curve and thus a faster cost reduction rate. Next, in Section 3.2, we consider the case where only the initial cost of production of the solar technology decreases by a learning rate, while the cost of production of wind is constant. This can be motivated by the fact of having a novel technology with high learning rates and an older or even obsolete one. Finally, in Section 3.3, we consider the cost of the solar PV technology to be stochastic and keep the price of energy deterministic. The latter can be motivated by the fact that there are many government policies, such as feed-in tariffs, that keep prices quite stable.

\subsection{The costs of both technologies decrease with a learning rate}

We start by considering the case in which the cost curves of both technologies decrease over time by (distinct) learning rates. The idea is shown in Figure 1: the initial cost of solar is higher than the cost of wind $\left(c_{s}>c_{w}\right)$, but its learning rate is higher too $\left(\gamma_{s}>\gamma_{w}\right)$. This means that at some point in time the two costs curves intersect, resulting in a so-called break-even point $\left(t_{B}\right.$, $C_{B}$ ) where the cost of the solar and wind technologies are equal. Beyond that point, as a result of the faster learning rate of solar, its cost becomes lower than that of wind definitely and ever more so.

In our problem, time is continuous and the duration of investment impacts or the lifetime of the technologies is considered for both to be equal to $T$. The firm holds the option to invest and develop two different technologies where, in this first case, one is characterized by a learning curve.

At the initial time, the firm has no capital invested in neither of the two technologies. The investment is considered to be irreversible and associated with a lump sum up-front cost which is different for the two technologies. A unit of capital cost $i$, so investment in $K$ units of capital requires an investment expense of $I(K)=i K$. This capital will be divided between the two technologies, $k_{s}$ and $k_{w}$. Once in place, the lifetime of the facility is considered to be infinite.

Each unit of output is produced at a non-negative marginal cost. The learning curves allow the firm to decrease these costs with accumulated experience. At each point in time, marginal costs are constant with respect to the rate of output but starting from an initial level $c_{s, 0}$ and $c_{w, 0}$ they decline with cumulative output $Q$.

At each point in time, $Q_{s, t}$ and $Q_{w, t}$ represent the cumulative demand for solar and wind energy at time $t$, and are given by: 


$$
\begin{aligned}
& Q_{s, t}=\int_{0}^{T} q_{s, \tau} d \tau \\
& Q_{w, t}=\int_{0}^{T} q_{w, \tau} d \tau
\end{aligned}
$$

The cost curves of the two technologies are presented in Figure 1. The vertical line represent the cost for the two technologies in Euros and the horizontal line the time.

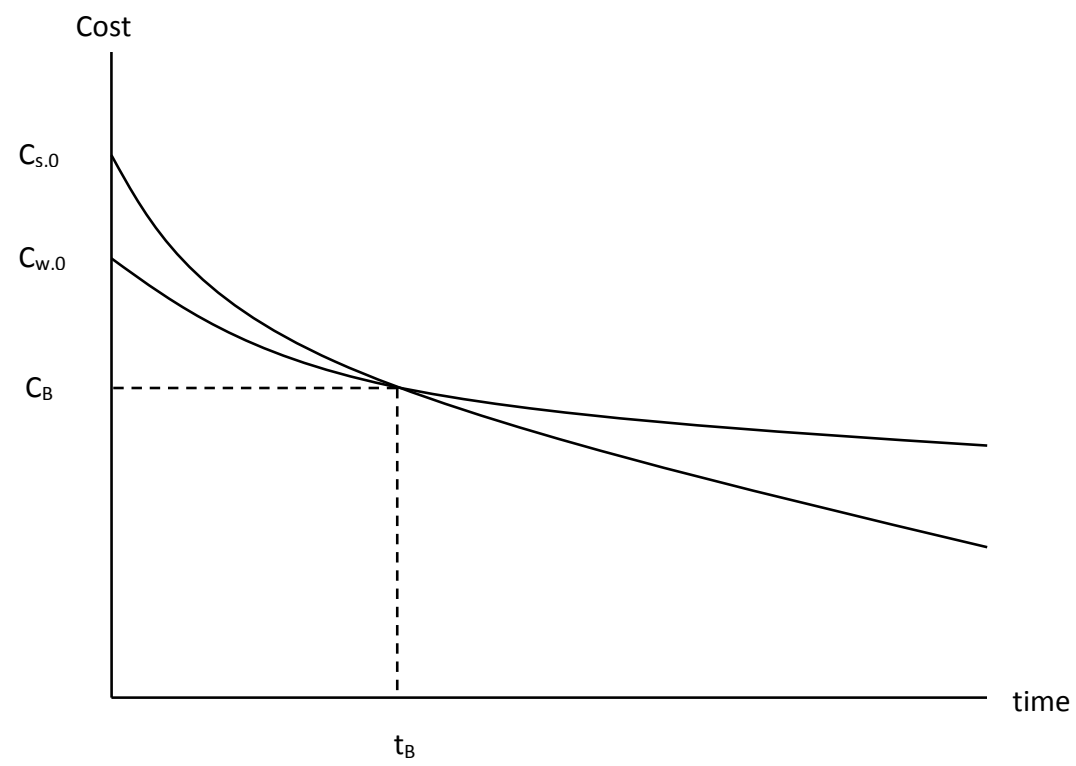

Figure 1 Cost curves of wind and solar decreasing due to learning

The cost curves start at different initial cost levels. $C_{S}$ is the yearly cost of production and maintenance of the solar panels, and $C_{w}$ is the annual cost of investment and maintenance of wind turbines. The initial cost of the $C_{s}$ curve is higher than that of the $C_{w}$ curve. In addition, the cost of the solar PV technology decreases over time with a learning rate $\gamma_{s}$, while the cost of the wind technology decreases with $\gamma_{w}$.

To model the learning curve we follow Majd and Pindyck (1989) and define the instantaneous marginal costs for solar and wind energy as follows:

$$
\begin{aligned}
& C_{s, t}=c_{s, 0} e^{-\gamma_{s} Q_{s, t}} \\
& C_{w, t}=c_{w, 0} e^{-\gamma_{w} Q_{w, t}}
\end{aligned}
$$

The components $\gamma_{s}$ and $\gamma_{w}$ describe the learning curve for the two different technologies, i.e. solar and wind, respectively. The parameters $\gamma_{s}$ and $\gamma_{w}($ both $>0)$ determine the speed of the learning process (translating in cost reduction). A high (low) value means that the learning curve is steep (flat). As illustrated in Figure 1, we can see that the slope of the cost curve for solar energy (in absolute values) is higher than that of the wind technology $\left(\gamma_{s}>\gamma_{w}\right)$.

In addition, from Figure 1, we can see that the slope of the cost curve for solar starts at a higher initial cost, but then, as a result of learning decreases over time.

The firm's output is non-storable and sold at a unit market price denoted by $P_{t}$. The investment is done at time $t_{0}$ and the technologies become obsolete at time T. The net present value of the total profits over the time period is then equal to: 


$$
N P V=\int_{0}^{T} \pi_{t} e^{-\rho t} d t
$$

Profits are discounted at rate $\rho$.

Here $\pi_{\mathrm{t}}$ is the total profit obtained from the investments in the two technologies, equal to the sum of profits from each technology, solar and wind:

$$
\pi_{t}=\pi_{s, t}+\pi_{w, t}
$$

The profits from solar are equal to its revenues minus its costs, with $c$ the decreasing cost curve due to cumulative learning:

$$
\pi_{s, t}=\left(P_{t}-c_{s, t}\right) k_{s, t}
$$

In the same way, the profits from wind are equal to:

$$
\pi_{w, t}=\left(P_{t}-c_{w, t}\right) k_{w, t}
$$

In these two equations, $k_{s, t}$ and $k_{w, t}$ denote the quantities of capital invested in the two technologies at each point in time. $P_{t}$ is the price from selling the energy (electricity) produced and is equal for wind and solar since their outputs are identical and so perfect substitutes.

We assume that the price is determined by an inverse linear demand function (Della Seta et al., 2012):

$$
P_{t}=a-b\left(q_{s, t}+q_{w, t}\right)
$$

This simply reflects that more supply leads to a lower price. In equation (9), we consider $b$ as a strictly positive constant and $a$, the demand shift parameter, fluctuates according to a geometric Brownian motion with drift $\alpha$ and standard deviation $\sigma$. The drift factor implies that the price will follow an increasing trend over time.

$$
d a=\alpha a d t+\sigma a d z_{t}
$$

We require that $\rho>\alpha$ because if not is not convenient to invest.

The per-period profit for solar can be written as a function of demand shock $a$, capital stock $K$ and cumulative output $Q$.

$$
\pi_{s}=\left[P_{t}-c_{s, 0} e^{-\gamma_{s} Q_{s, t}}\right] k_{s, t}=\left[a-b\left(k_{s}+k_{w}\right)-c_{s, 0} e^{-\gamma_{s} Q_{s, t}}\right] k_{s}
$$

And for wind:

$$
\pi_{w}=\left[P_{t}-c_{w, 0} e^{-\gamma_{w} Q_{w, t}}\right] k_{w, t}=\left[a-b\left(k_{s}+k_{w}\right)-c_{w, 0} e^{-\gamma_{w} Q_{w, t}}\right] k_{w}
$$

We assume a simple linear production function for translating capital inputs into solar and wind energy output $q_{s, t}=k_{s, t}$ and $q_{w, t}=k_{w, t}$. Total profits can then be written as:

$$
\pi_{t}=\left(a-b\left(k_{s}+k_{w}\right)\right)\left(k_{s}+k_{w}\right)-\left(c_{s, 0} k_{s} e^{-\gamma_{s} k_{s, t}}+c_{w, 0} k_{w} e^{-\gamma_{w} k_{w, t}}\right)
$$


Then the net present value is given by equation (14) below

$$
\begin{aligned}
& N P V(\pi)=\int_{0}^{T}\left(a K-b K^{2}-c_{s, 0} k_{s} e^{-\gamma_{s} k_{s} t}-c_{w, 0} k_{w} e^{-\gamma_{w} k_{w, t}}\right) e^{-\rho t} d t \\
= & \frac{a_{0} K\left(1-e^{-(\rho-\alpha) T}\right)}{(\rho-\alpha)}-\frac{b K^{2}\left(1-e^{-\rho T}\right)}{\rho}-\frac{c_{s, 0} k_{S}\left(1-e^{-\left(\gamma_{s} k_{S}+\rho\right) T}\right)}{\rho+\gamma_{s} k_{S}}-\frac{c_{w, 0} k_{w}\left(1-e^{-\left(\gamma_{w} k_{w}+\rho\right) T}\right)}{\rho+\gamma_{w} k_{w}}
\end{aligned}
$$

Taking the real option perspective, the firm or community can be seen as holding an American call like option. The firm with exercise the option at the critical time threshold, $a^{*}$, at which, accounting for the uncertainty in the price of electricity, the initial cost of the two technologies and the learning curves, investing gives the maximum benefit to the firm.

Denoting by $F(a)$ the value of the option to invest in the two technologies, the value of such an option is given by:

$$
F(a)=e^{-\rho t} E[F(a+d a)]
$$

By using Ito's Lemma we expand the RHS of the equation to obtain:

$$
\frac{\sigma^{2}}{2} a^{2} F^{\prime \prime}(a)+\alpha a F^{\prime}(a)-\rho F(a)=0
$$

The solution of (16) takes the following functional form: ${ }^{1}$

$$
F(a)=A_{1} a^{\beta_{1}}
$$

where $\beta_{1}$ is the positive root of the characteristic equation obtained by substituting eq. 17 in eq. 16: $\left(\frac{1}{2}\right) \sigma^{2} \beta(\beta-1)+\alpha \beta-\rho=0$, with $A_{1}$ a constant to be determined.

The value of the option and the critical exercise threshold can be determined by imposing value matching and smooth pasting conditions at $a^{*}$. That is:

$$
F\left(a^{*}\right)=N P V\left(a^{*}\right), F^{\prime}\left(a^{*}\right)=N P V^{\prime}\left(a^{*}\right)
$$

The system (18) is solved for $a^{*}$. It follows that:

$$
a^{*}=\left(\frac{\beta_{1}}{\beta_{1}-1}\right)\left[\frac{\frac{b K^{2}\left(1-e^{-\rho T}\right)}{\rho}+\frac{c_{s, 0} k_{S}\left(1-e^{-\left(\gamma_{s} k_{s}+\rho\right) T}\right)}{\rho+\gamma_{s} k_{S}}+\frac{c_{W, 0} k_{W}\left(1-e^{-\left(\gamma_{w} k_{W}+\rho\right) T}\right)}{\rho+\gamma_{w} k_{W}}}{\frac{K\left(1-e^{-(\rho-\alpha) T}\right)}{(\rho-\alpha)}}\right]
$$

The value of the option takes the form:

$$
F(a)= \begin{cases}N P V\left(a^{*}\right)\left(\frac{a}{a^{*}}\right)^{\beta_{1}} & \text { for } a<a^{*} \\ N P V(a) & \text { for } a>a^{*}\end{cases}
$$

\footnotetext{
1 The general solution to equation (16) is $F(a)=A_{1} a^{\beta_{1}}+A_{2} a^{\beta_{2}}$, where $\beta_{1}>1$ and $\beta_{2}<0$ are the roots of $F(\beta)=$ 0 and $A_{1}$ and $A_{2}$ are two constants to be determined. Since the option to invest should increase as $a \rightarrow \infty$, the second term must be dropped, implying $A_{2}=0$.
} 
The critical threshold $a^{*}$ represents the optimal threshold in the stochastic energy prices where the firm decides to invest in the two technologies. For energy prices lower than $a^{*}$, the firm should keep the option to invest, while for energy prices higher than $a^{*}$, the firm should exercise the option and invest in the two technologies. The amount of investment to address to each of the two technologies depends on the initial cost, the learning curves, the drift and volatility of energy prices, and the discount rate. In order to provide a numerical solution on the different combinations on capital in the two technologies the technology invested in the solar PV technology is considered as $\delta K$ while the capital invested in the wind technology as $(1-\delta) K$.

\subsection{Cost of solar PV technology with a learning rate while the costs of wind fixed}

In this section we continue by considering the cost of one of the technologies (wind) as constant and the cost of the other (solar) following a learning curve, which causes it to decrease over time. This can be interpreted as a new technology arriving to the market, thus having great potential to reduce its costs due to learning; and having in addition an old, mature and possibly obsolete technology, whose costs are at a historical minimum and constant for the remaining time.

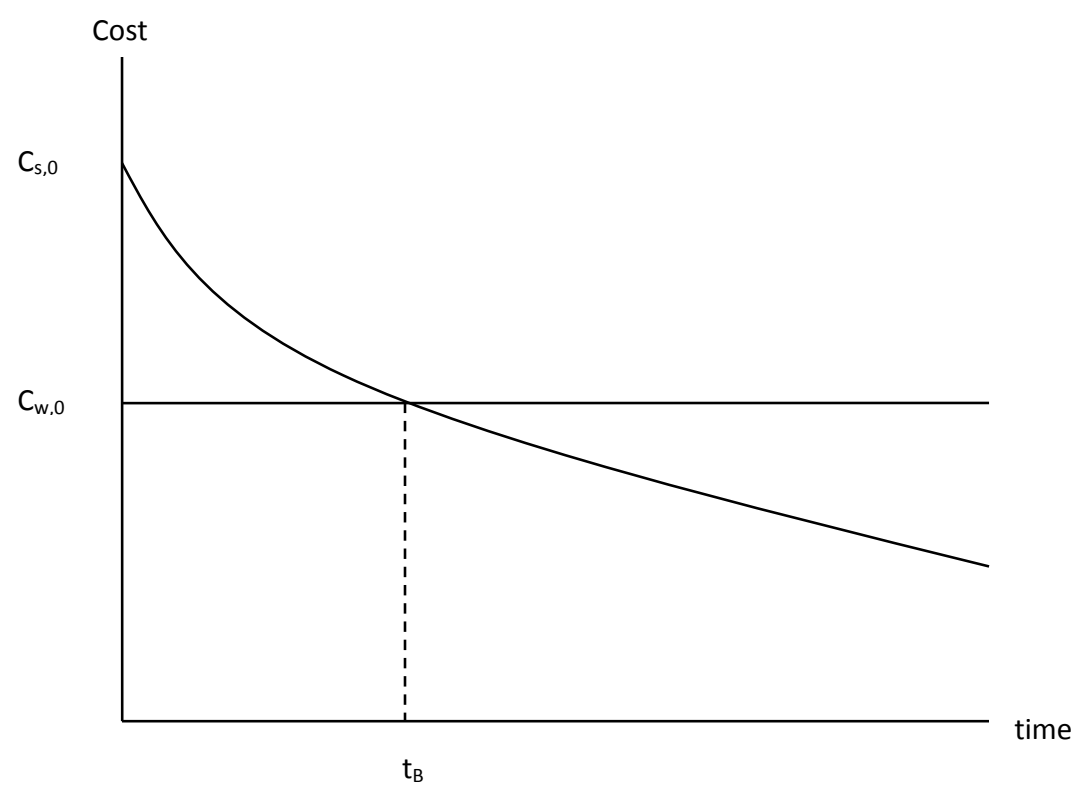

Figure 2: Cost curves for wind (constant) and solar (decreasing due to learning)

To model the learning curve we again follow Majd and Pindyck (1989). The cost curve of the solar technology is still expressed by equation 3 , while the cost curve of the wind technology is expressed by equation 21 below.

$$
C_{w, t}=c_{w, 0}
$$

This assumption simplifies the model considerably while still reflecting that the relative cost of wind, compared with that of solar PV, is increasing as the latter follows a learning curve.

We still conserve equation 11 expressing the per-period profit for solar, while the per-period profit of wind is now given by:

$$
\pi_{w}=\left[P_{t}-c_{w, 0}\right] k_{w, t}=\left[a-b\left(k_{s}+k_{w}\right)-c_{w, 0}\right] k_{w}
$$


The total profit will then be equal to:

$$
\pi_{t}=\left[a-b\left(k_{s}+k_{w}\right)-c_{s, 0} e^{-\gamma_{s k_{s} t}}\right] k_{s}+\left[a-b\left(k_{s}+k_{w}\right)-c_{w, 0}\right] k_{w}
$$

Then the net present value is given by equation (24) below

$$
\begin{array}{r}
N P V(\pi)=\int_{0}^{T}\left(a K-b K^{2}-c_{S, 0} k_{s} e^{-\gamma_{s} k_{s} t}-c_{w, 0} k_{w} e^{\left.-\gamma_{w k_{w} t}\right)} e^{-\rho t} d t\right. \\
=\frac{a_{0} K\left(1-e^{-(\rho-\alpha) T}\right)}{(\rho-\alpha)}-\frac{b K^{2}\left(1-e^{-\rho T}\right)}{\rho}-\frac{c_{S, 0} k_{S}\left(1-e^{-\left(\gamma_{s} k_{s}+\rho\right) T}\right)}{\rho+\gamma_{s} k_{s}}-\frac{c_{w, 0} k_{w}\left(1-e^{-\rho T}\right)}{\rho}
\end{array}
$$

By following the steps $15-18$ as in the first case, we arrive at the critical threshold

$$
a^{*}=\left(\frac{\beta_{1}}{\beta_{1}-1}\right)\left[\frac{\frac{b K^{2}\left(1-e^{-\rho T}\right)}{\rho}+\frac{c_{S, 0} k_{S}\left(1-e^{-\left(\gamma_{s} k_{S}+\rho\right) T}\right)}{\rho+\gamma_{s} k_{S}}+\frac{c_{W, 0} k_{W\left(1-e^{-\rho T}\right)}}{\rho}}{\frac{K\left(1-e^{-(\rho-\alpha) T}\right)}{(\rho-\alpha)}}\right]
$$

\subsection{Uncertainty about the learning rate of solar and deterministic electricity price}

In the third case we consider price as deterministic. This means that in equation 9 the components $a$ and $b$ are now both constant and positive. It can be interpreted as the price of electricity being fixed, or having a large deterministic component, due to governmental support mechanisms such as feed-in tariffs, while the cost of the technology decreases over time as a result of learning and innovation. This model version allows us to examine the effect of uncertainty about costs, in particular learning rates. Including both price and cost uncertainty will lead to an overly complicated model, and moreover can be argued to be unnecessary as cost uncertainty will affect price patterns, so that indirectly prices are uncertain as a result.

We assume the cost of solar PV to follow a geometric Brownian motion as in equation 26.

$$
d C_{s, 0}=\alpha C_{s, 0} d t+\sigma C_{s, 0} d z_{t}
$$

As in the previous case, we let the initial cost of production of solar PV to decrease with its learning rate. For this reason, we put the drift equal to zero and investigate on different values of volatility to analyze the effect of uncertainty in technology costs.

The per-period profit equations are expressed by equations 22 and 23 of the previous section. We then follow the steps 15-18 to arrive at the critical threshold of the cost of solar PV technology which is expressed by equation 27 :

$$
c_{S, 0}^{*}=\left(\frac{\beta_{1}}{\beta_{1}+1}\right)\left[\frac{\frac{a K\left(1-e^{-\rho T}\right)}{\rho}-\frac{b K^{2}\left(1-e^{-\rho T}\right)}{\rho}-\frac{c_{W, 0} k_{W}\left(1-e^{-\rho T}\right)}{\rho}}{\frac{k_{S}\left(1-e^{-\left(\gamma_{s} k_{S}+\rho\right) T}\right)}{\rho+\gamma_{S} k_{S}}}\right]
$$

This equation defines the maximum value of the initial electricity production cost of the solar PV technology for which, given the revenues generated by the investment, it is profitable to exercise the option. For every value of electricity production cost of the solar technology above this critical threshold, it is not convenient to invest and one will maintain the option to invest 
open. For every value equal or below this level, it is profitable to exercise the option to invest and allocate different shares of capital (depending on the level of cost and learning rate) to the solar PV technology. The choice of shares is illustrated in the next section.

\section{Numerical application}

Since insightful analytical solutions are impossible because of nonlinearities in the model, here we perform numerical analysis with the models to understand the characteristics of optimal investment in wind and solar technologies.

Table 3 shows the values of the parameters for the three cases.

Table 3 Default values of model parameters for numerical simulations

\begin{tabular}{|c|c|c|c|c|}
\hline Description & Symbol & Case 1 & Case 2 & Case 3 \\
\hline $\begin{array}{l}\text { Learning rate of the solar } \\
\text { technology }\end{array}$ & $\gamma_{s}$ & 0.05 & - & 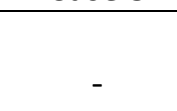 \\
\hline $\begin{array}{l}\text { Learning rate of the wind } \\
\text { technology }\end{array}$ & $\gamma_{w}$ & 0.03 & 0 & - \\
\hline Demand parameter & $b$ & 0.2 & - & - \\
\hline Drift & $\alpha$ & 0.04 & - & 0 \\
\hline Volatility & $\sigma$ & 0.1 & - & - \\
\hline Discount rate & $\rho$ & 0.06 & - & - \\
\hline $\begin{array}{l}\text { Intial cost of electricity } \\
\text { production by the solar } \\
\text { technology } \\
\text { Initial cost of electricity } \\
\text { production by wind }\end{array}$ & $c_{s, 0}$ & 20 & - & $\begin{array}{l}\text { Solved by } \\
\text { the model }\end{array}$ \\
\hline technology & $c_{w, 0}$ & 15 & - & - \\
\hline $\begin{array}{l}\text { Root of fundamental } \\
\text { quadratic equation } 16 \\
\text { Capital invested in the }\end{array}$ & $b_{1}$ & 1.4244289 & - & - \\
\hline two technologies & $K$ & 100 & - & - \\
\hline Investment duration & $T$ & 25 & - & - \\
\hline Price intercept parameter & $a$ & $\begin{array}{l}\text { Solved by } \\
\text { the model }\end{array}$ & $\begin{array}{l}\text { Solved by } \\
\text { the model }\end{array}$ & 35 \\
\hline
\end{tabular}

\subsection{Both technologies with learning}

In this case we both the learning curves of the two technologies decreasing with a learning parameter. We set the preliminary condition $\gamma_{s}>\gamma_{w}$, as a result the cost curve of solar will be steeper than the one of the wind technology. Thereby, the costs of the solar technology start at a higher initial cost, but perhaps decrease more rapidly compared to the one of the wind technology. The learning parameters for the base case are set equal to 0.05 for the solar and 0.03 for the wind technology.

Figure 3 shows the critical threshold $a^{*}$ for different portions of capital invested in the two technologies. As it can be seen from the figure, when all the edges of the graph show the lower $a^{*}$ value that makes us exercise the option to invest. 


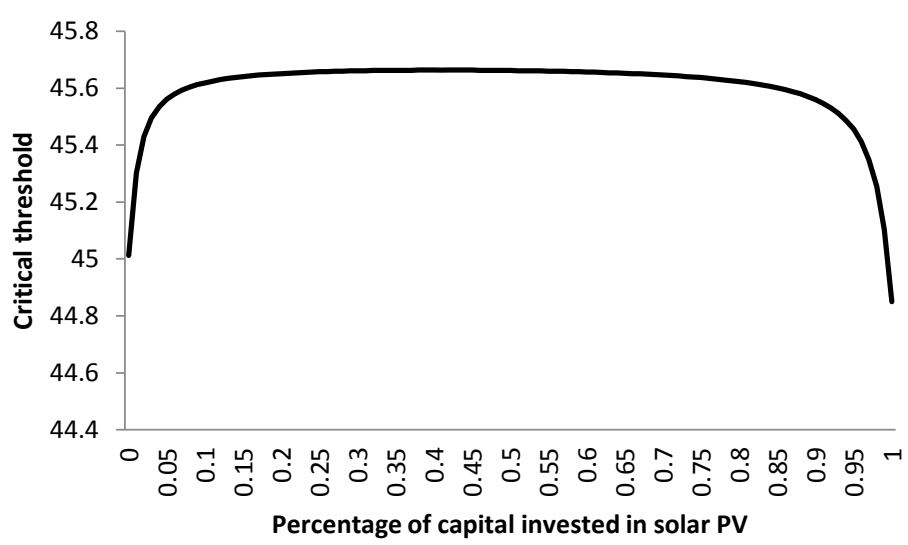

Figure 3 Critical threshold with two learning curves

This is a straight forward result of our model since the amount of capital invested has a direct effect on learning and as a result on the costs decrease. Even if solar starts at an initial cost which is higher, compared to the wind technology, as a result of the higher learning parameter, the costs of this technology decrease faster. As a result, we are willing to invest in the solar technology at $a^{*}=44.84$, while to invest $100 \%$ of our capital in wind, we will wait more, until $a^{*}$ reaches 45.01 . However, we are considering the case of an investor who wants to diversify his investment in the two technologies. From the graph we can see that if the price of electricity is below 45.01, then it is profitable to invest all the capital in the solar technology. If the price increases up to 45.40 it is profitable to allocate $95 \%$ of the capital in one technology and only $5 \%$ in the other. This is because we have to account for the costs of the two technologies, and the fact that cost are falling due to both learning and more capital being invested in a particular technology. This means that investing more capital in one technology generates faster learning and thus reduction of electricity production costs associated with the respective technology. By diversifying the investment, the cost reduction will not be as high. As a result we will postpone the investment and require a higher $a^{*}$ to exercise the option to invest. The higher value of $a^{*}$ is 45.66349 and the allocation of capital is $\$ 41$ in the solar technology and the remaining $\$ 59$ in the wind technology.

Figure 4 shows the sensitivity analysis of the learning parameter and initial cost in the case when the costs of wind and solar electricity production are affected by learning.
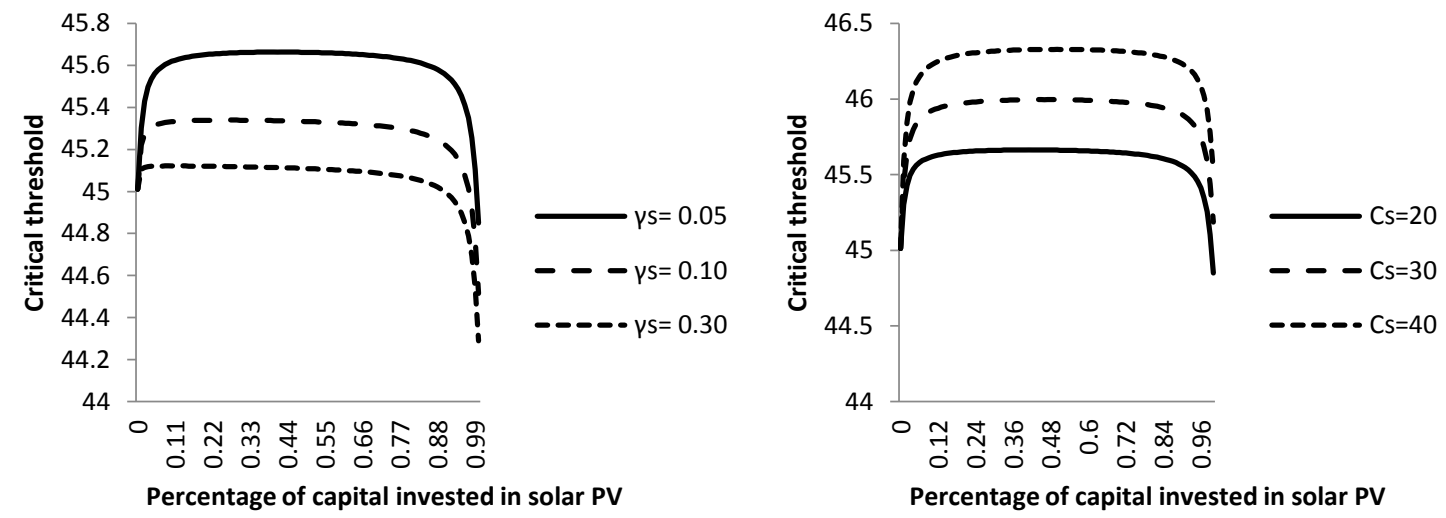

Figure 4 Sensitivity analysis of learning and initial cost 
As in the case with one cost curve with learning, the effect of an increase in the learning parameter does anticipate the option to invest and decrease the critical threshold as shown form the right graphin Figure 4. When the learning parameter of solar is equal to 0.30 , it is profitable to exercise the option to invest at a price equal to 44.29 and invest $100 \%$ of the capital in the solar PV technology, and hence benefit from its high learning speed. An increase in the initial cost of solar does postpone the option to invest and increase the critical threshold. The right graph in of Figure 4.4 shows that when the cost of solar is equal to 20 , as in the base case, we exercise the option to invest earlier and allocate $100 \%$ of the capital in the solar technology. As Figure 4 shows, when the initial cost of solar is equal to 40 , the order of investment is reversed. For electricity prices equal to 45.01 it is profitable to invest $100 \%$ of the wind, and the firm has to wait until the price goes up to 45.52. The highest critical threshold at which we exercise the option to invest is equal to 46.32 for the distribution of capital $50 \%$ in solar PV and $50 \%$ in wind.

Figure 5 shows the results of the sensitivity analysis on the volatility of energy prices. The pattern of the lines is the same, but perhaps we will require a lower critical value to exercise the option to invest if there is no volatility in energy prices. In this case, $a^{*}=40.09$ if all capital is invested in the solar PV technology.

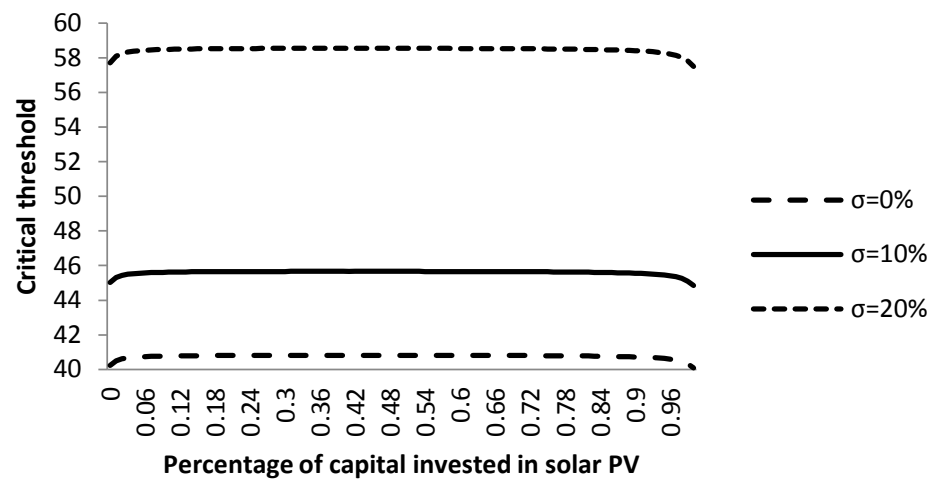

Figure 5 Sensitivity analysis on volatility

If the volatility in energy prices is quite high, equal to $20 \%$, the decision to invest will be postponed until $a^{*}=57.50$ to invest all the capital in the solar PV technology or even higher if we consider a combination of the two technologies. As explained earlier, in order to diversify the investment, the firm will wait until the price of electricity is high enough to cover the costs of both technologies since costs will decrease at a lower rate.

\subsection{One technology with learning}

Here we examine the case when only the costs of the solar technology decrease with a learning rate, while the costs of the wind technology are kept constant during the lifetime of the technology. The other parameters are set as indicated in Table 3.

The critical threshold $a^{*}$ at which it is profitable to exercise the option to invest is given by Figure 6. 


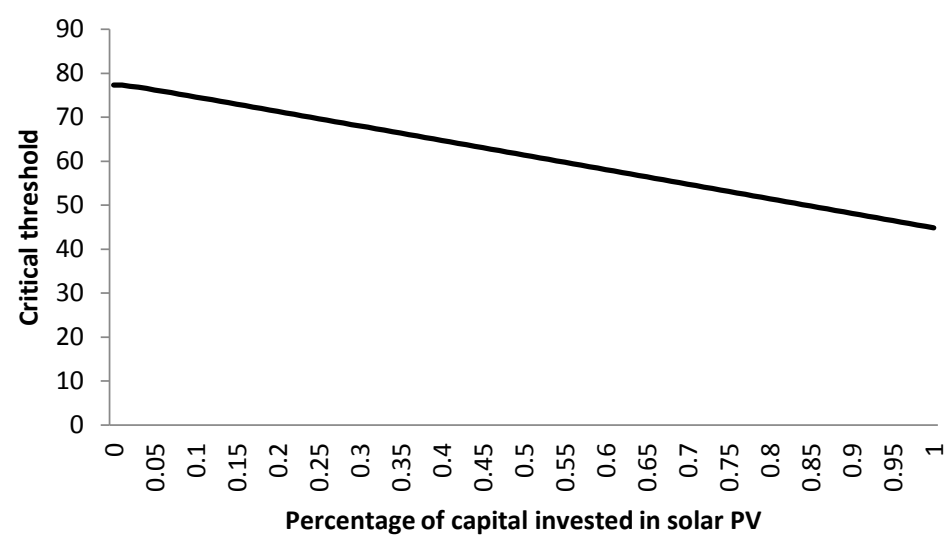

Figure 6 Critical threshold $a^{*}$ at which it is profitable to exercise the option

The figure shows that if all capital is invested in the technology with fixed costs, then we postpone the option to invest and require a high value of $a^{*}\left(a^{*}=77.31\right)$. As we diversify our investment and invest an increasing part of capital in the solar technology, its costs decreasing with the learning rate, causing exercising of the option to invest to be optimal at lower, decreasing values of $a^{*}$. If capital investment is diversified as $50 \%$ in the solar and the remaining $50 \%$ in the wind technology, then the option is exercised for an electricity price equal to 61.41 . If all the capital is invested in the solar technology, then we are willing to exercise the investment earlier at a minimum value of $a^{*}=44.84$, i.e. also for any value larger than this.

Figure 7 shows the relationship between the learning rate and the critical threshold on the left side, and between the initial cost and critical threshold on the right side, both for the case where $50 \%$ of the capital is invested in solar PV and $50 \%$ in wind technology.

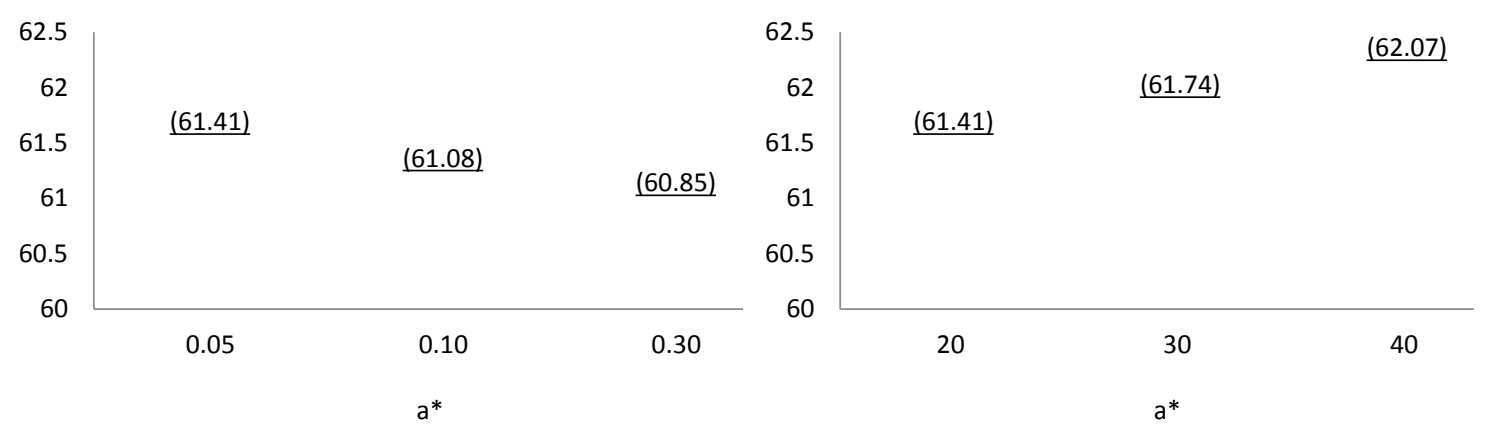

Figure 7 Sensitivity analysis of the impact of learning and initial cost on the critical threshold

The figure shows that the higher the learning rate, the earlier we exercise the option to invest and for lower values of $a^{*}$, as a result of the cost reduction. On the contrary, the higher the initial cost of the solar technology, the later one invests on average and a higher value of $a^{*}$ is required. The uncertain time delay results from the fact that prices steadily increase but stochastically. In addition, the costs of production of the solar technology will start at a high value, and even if it falls due to learning, it will be relatively high for a long period. For this reason one will be forced wait and require a higher critical threshold price to exercise the option.

In Figure 8 we show a sensitivity analysis of volatility. In line with the literature on real options, we can see that the higher the volatility in the market, the more we are willing to postpone the investment and require a higher value $a^{*}$ before executing the option. 


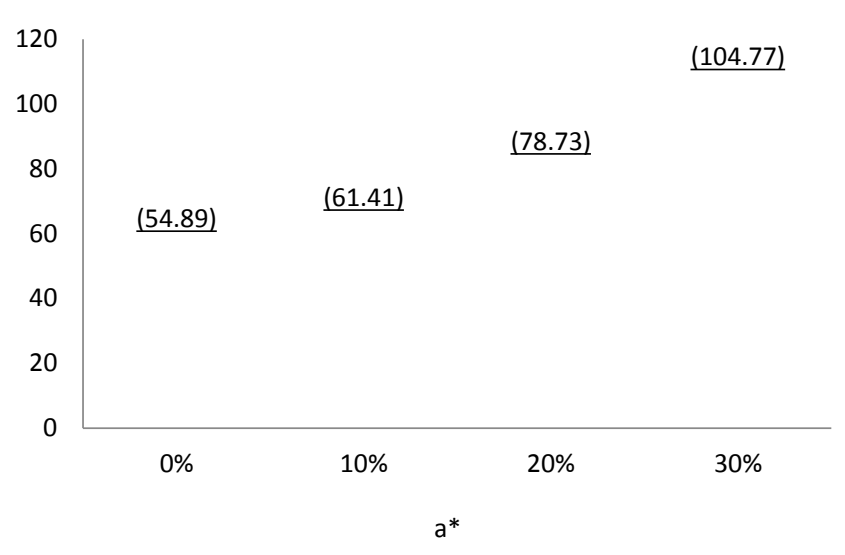

Figure 8 Sensitivity analysis of volatility

If volatility is equal to zero and we invest all our capital in the technology with learning, we are willing to invest at a critical threshold of 54.89. On the contrary, if volatility in the market is high, equal to $30 \%$, we wait to invest until the critical threshold is equal to 104.77 . This holds for the case of the investor diversifying investment $50 \%$ in solar and $50 \%$ in wind.

Figure 9 shows the effect of $\gamma_{s}$ on timing and the critical threshold for $\sigma$ equal to $0.05,0.1$ and 0.2. As expected, for a given learning rate in the solar technology, the critical threshold increases with uncertainty.

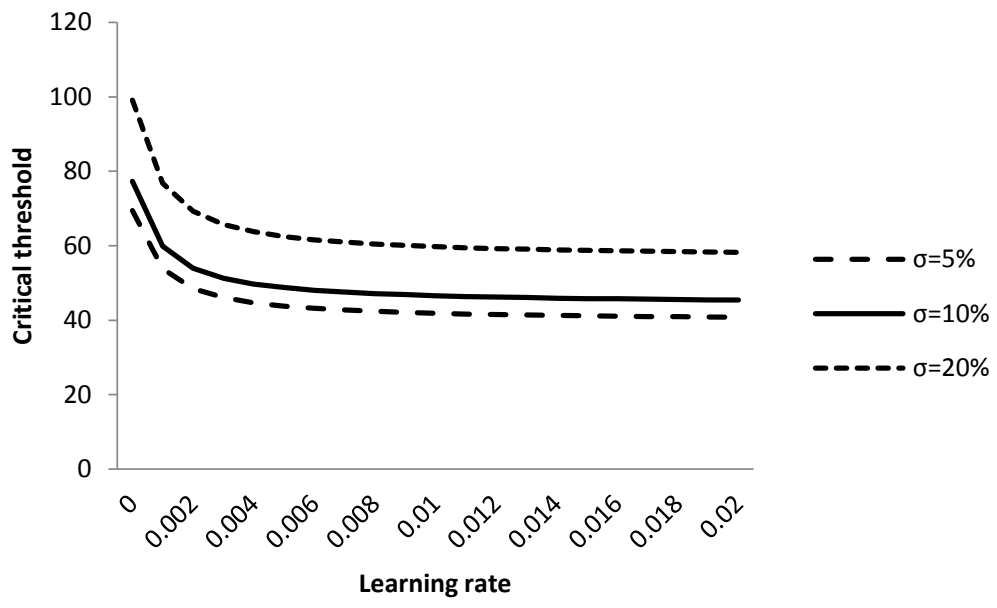

Figure 9 Optimal values of the critical threshold for different values of volatility

If the learning rate is low and volatility high, we will postpone the option to invest and require very high values of $a^{*}$ to exercise the option. As the learning rate increases, or volatility in energy prices decreases, we anticipate the option to invest and $a^{*}$ decreases in value.

Figure 10 shows the option value and the NPV curve. The straight line showing NPV indicates that it is profitable to invest as soon as NPV $>0$. 


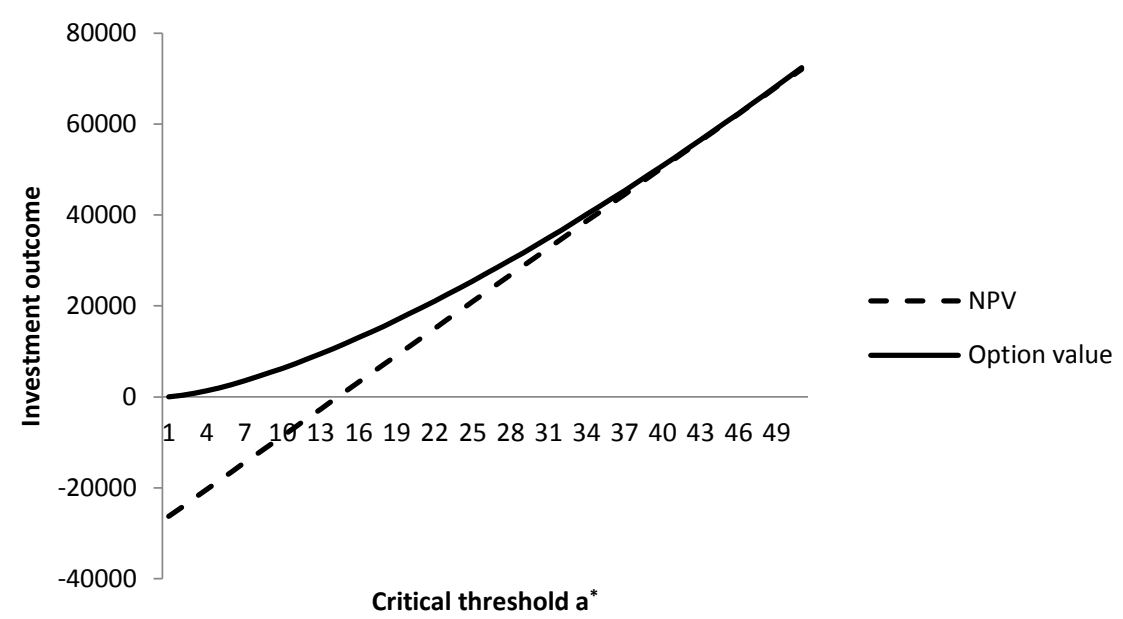

Figure 10 Net present value and option value compared

By investing all the capital in the technology with learning, the NPV of the investment becomes positive for a value of $a^{*}$ equal to 13.31. According to the real options theory, the value of the option to wait, is given by the red line $F(a)$.

$$
F(a)= \begin{cases}A_{1} a^{\beta_{1}} & \text { for } a<a^{*} \\ N P V & \text { for } a>a^{*}\end{cases}
$$

According to the NPV we should invest $100 \%$ of our capital in the technology with learning as soon as $a^{*}=13.31$. However, from the figure, we can see that the option has a high value in this point. By investing we kill this option value. Following Figure 4.10, we have to wait until the option value equals NPV and then exercise the option to invest. This means that the investor should wait until $a^{*}$ is equal or greater than 44.62. At this point the option value is zero and its curve touches the NPV curve as shown in the figure. In order to diversify its investment in the two technologies, the investor should exercise the option for values in the electricity price higher than 44.62 .

\subsection{One technology with learning, deterministic price and stochastic costs.}

In this part of our study we consider price as deterministic. The price equation (9) still applies, but with fixed parameters $a$ and $b$, both strictly positive. Figure 11 shows that maximum value of the initial cost of electricity production by the solar technology at which we are willing to invest according to the NPV and the real options approach. 




Figure 11 Initial cost of solar PV according to NPV and real options

According to this figure, investing little capital in the solar PV technology (i.e. exercising the option to invest) is optimal only if the initial production cost is sufficiently low. On the contrary, a high share of capital invested in solar is optimal already for higher production costs since one has the expectation here that production costs drop rapidly due to faster learning. The reason is that the more capital is invested in solar, the faster its costs drop due to learning. This result derives from the fact that all capital is invested in solar PV and hence the firm can cover higher production costs for this technology. Following the NPV curve, we should invest in the technology and accept even a higher initial production cost before exercising the option. The real options approach, which is more accurate since it considers the volatility in production costs, tells us to wait and not exercise the option to invest until costs are equal or below the value represented by the continuous "Real Options" line.

Figure 12 shows a sensitivity analysis of the impact of the $a$ parameter of price on the threshold of the initial cost.

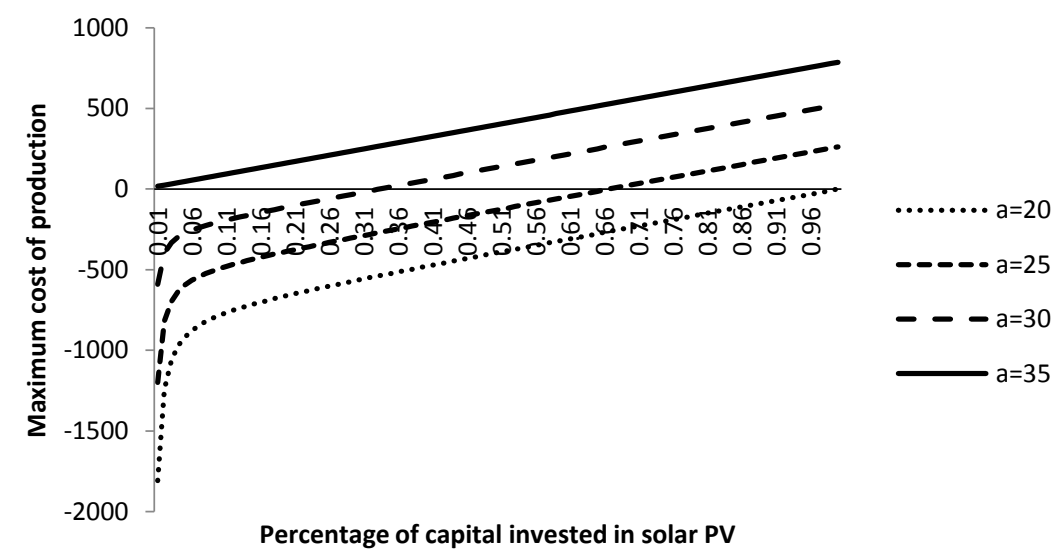

Figure 12 Sensitivity analysis of the price intercept a

In Figure 12, for $a=20$, the electricity price is too low to give sufficient revenues, even if the initial cost of solar PV is equal to zero. This means it is not profitable to invest any proportion of the capital in solar PV technology. When $a=25$, as a result of the costs decreasing due to learning it is profitable to invest a large amount of capital in solar PV. As shown in the figure at least $67 \%$ of all capital needs to be invested in solar to make execution of the option viable. Raising 
parameter $a$ further, to 30 , the share threshold goes down to $34 \%$. For values of $a$ beyond 35 any investment in solar PV is viable.

Figure 13 shows the sensitivity analysis of the impact of volatility on the initial cost of solar.

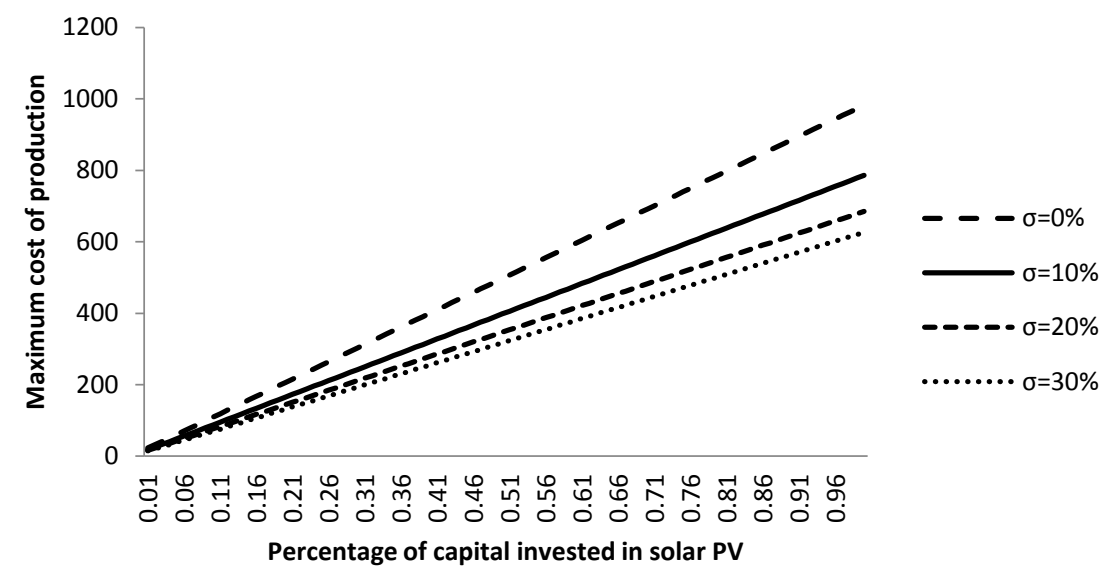

Figure 13 Initial cost of technology of solar PV and volatility

The figure shows that the lower the volatility, the higher the maximum cost we are willing to accept to invest some share of capital in the solar PV technology. This is because with lower volatility the chance of positive spikes in costs is lower. In Figure 13, the line representing $\sigma=0$ coincides with the NPV line. For high values of volatility in the initial costs, one is eager to postpone the investment and wait until costs go down, as illustrated by the bottom line in the figure $(\sigma=30)$. This result is in line with the literature on real options where a general finding is that uncertainty postpones the investment.

The results of a sensitivity analysis of the learning rate are shown in Figure 14.

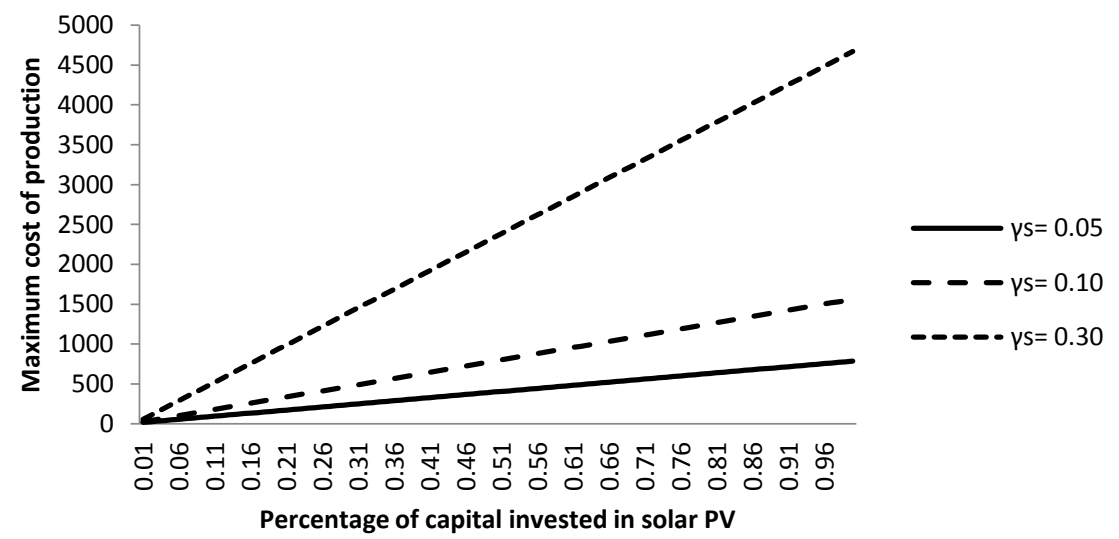

Figure 14 Sensitivity analysis of the learning rate

The figure shows that a low value of the learning rate postpones the decision to invest and makes one will wait until the initial cost of the solar PV technology decreases to the level as indicated by the continuous line showed in Figure 14. If the learning rate of the technology is very high, up to 0.30 , then, since costs decrease more over time with a higher rate, we exercise the option earlier and at even higher levels of initial cost. The higher the portion of capital invested in the solar PV technology, the higher will be the maximum cost that we accept to 
invest, since the investment can benefit more from the technology that allows learning over time and as a result making more revenues from the associated cost reduction.

\subsection{Comparison of the three model versions}

In the three applications illustrated above, we showed the different roles of the learning rate, the cost of the technology and uncertainty in investments in renewable energy projects. In first place, we pointed out the difference between the NPV and the real options approach. While the first indicates that we should invest as soon as profits are equal or greater than zero, the latter, which more accurately takes into account the drift in future electricity prices and market uncertainty, indicates to wait and exercise the option later when conditions are more favorable.

The results of our model show that uncertainty has the same effect when considered in the electricity prices or technology costs. The higher the uncertainty, the more one is willing to wait before exercising the option. This fact is also explained by the necessity to wait and have more market information in periods of high uncertainty. With high uncertainty the critical threshold in energy prices will grow, and the firm will require a higher price to exercise the option to invest, thereby postponing the option to exercise. A high uncertainty of costs on the other side will lower the critical threshold of production cost indicating the maximum cost the firm is willing to exercise the option.

The effect of learning is quite important in anticipating the option to invest and exercising earlier the option. Learning is straight forward connected to cost reduction. As a result, the higher the learning rate, the higher will be the amount of cost we reduce during the whole investment duration. In addition, the learning parameter is also positively connected with the share of capital in order to reduce costs. The more capital we invest in one technology, the more we learn from that technology, and the more we reduce costs.

The cost of production on the other hand postpones the option to invest. The higher the initial cost of production of the technology, the higher will be the price of electricity required to exercise the option to invest in order to make enough revenues to cover such cost. For this the investment will be postponed until prices will be at a higher level.

In the last part of our application we saw that by applying a fixed parameter of price, $a$, and having one technology with learning, we can identify the maximum initial cost that make this technology profitable and the share of capital we should invest in this technology. The results shown in Figure 12 indicate that for lower values of the parameter $a$ one is willing to wait and accept lower maximum costs of production to exercise the option to invest. This will influence the quantity of capital allocated to this technology. Since the amount of capital cumulatively invested affects the speed of learning, this allows a greater cost reduction. With a low guaranteed value of parameter $a$, one will be willing to allocate larger parts of capital to solar in order to realize a greater cost reduction. As soon as the $a$ parameter guaranteed is higher, a higher production cost can be accepted to exercise the option to invest and the size of capital allocated can be even smaller.

\section{Conclusions}

In this paper we presented the case of a firm or community having to decide between investing in two different types of renewable energy technologies, such as wind and solar PV. A fixed amount of capital available for investment has to be allocated between these two alternatives. In our study, the decision-maker considers the costs and benefits of diversification of investment in the two options. It is assumed that the electricity produced by both energy technologies is 
sold at a uniform price on the electricity market. We investigate three different cases: (i) the two technologies have distinct learning rates and initial costs of electricity production, while the electricity price is stochastic; (ii) only the production cost of one technology follows a learning curve, while the other has a constant cost, and again electricity price is stochastic; (iii) the electricity production cost of solar is stochastic and reduced by the learning parameter while the electricity price is deterministic due to public support like feed-in-tariffs.

Two critical features of the resulting decision problem is that investments in renewable energy are irreversible as a result of their high sunk costs, and that electricity prices and/or technology costs are uncertain (stochastic). To appropriate address such a decision problem, we applied real option theory. This is consistent with a growing literature which applies this theory to investments in renewable energy. The original contribution of this study was that it considered two distinct assets in which the firm can invest, with different initial cost and learning parameters. This responds to a recurrent public debate on whether we should focus on one renewable energy technology or support many technologies and keep uncertain options open. This is addressed with different types of methods in research, including evolutionary analysis and multi-criteria analysis (Skea, 2010; Stirling, 2010; van den Heuvel and van den Bergh, 2009; Shemelev and van den Bergh, 2016).

In the first two cases we solved the problem by determining the critical threshold at which the firm will invest in order to have a profit. For energy prices lower than this critical threshold, the firm should keep the option to invest, while for energy prices that are higher, the firm should exercise the option and invest in the two technologies. The results show that if $100 \%$ of the capital is invested in the solar PV technology or in the wind technology, the firm exercises the option earlier and at a lower critical threshold. In order to diversify the investment in the two technologies, the firm has to wait and exercise the option to invest at a higher critical threshold of electricity prices. This is because costs are reduced through learning which depends on the quantity of capital invested in a technology. The more we capital we invest in one technology, the more we learn and as a result cost reduction is greater for that technology, which makes it possible to exercise the option at a lower critical threshold. In the third case, we determine the maximum cost of production of a given technology that the firm will be willing to invest, and the given capital share of the two investments. The results here show that if the firm invests little capital in solar PV, then it has to wait and exercise the option to invest only if the initial production cost is sufficiently low. If the capital invested in the solar PV technology is high, then it is possible to earlier exercise the option to invest, and moreover for higher values in the initial cost. Two reasons for this result are: we invest more capital in solar PV, thereby decreasing the investment in wind; and since more capital is invested, the cost decrease as a result of learning will be higher, which allows the firm to cover higher production costs.

A high learning rate will translate in anticipating the option to invest, requiring a lower critical value to exercise the option in the first two cases, or accepting a higher initial production cost in the third case since it has a direct effect on cost reduction. The higher the learning rate of one technology, the earlier we exercise the option to invest and the larger will be the capital allocated to that technology. A high cost of technology will on the other hand postpone the option to invest, since the firm will need to make sufficient profits to cover the associated stream of costs during the entire period. The higher are the cost of a technology, the higher will be the price required to exercise the option to invest. An increase in the initial cost will postpone the option to invest and make the firm allocate more capital to the other technology. We find that 
high uncertainty in either electricity prices or technology costs will postpone the investment. Under high uncertainty one will prefer to wait more and see how the market evolves before exercising the option.

When prices are deterministic, the more capital the firm allocates to one technology the higher will be the maximum electricity production cost to exercise the option to invest. This means that for high shares of capital invested one can accept relatively high costs, while on the contrary, for low capital shares the firm will wait until the cost decreases sufficiently, otherwise it cannot cover this with the revenues made. Moreover, such production cost cannot quickly go down at a high rate due to learning when relatively little capital is invested. In the presence of a deterministic price supported through government subsidies, the results show that its level affects not only the maximum cost the firm can accept to exercise the option to invest, but also the share of capital between the two technologies. From this result we can see that governments employing policies to guarantee a minimum price, will - through reducing future price uncertainty - influence capital allocation between renewable energy options.

The somewhat surprising main insight from this study is that although investing in both solar and wind may be profitable, although it certainly is not under all conditions of price and cost uncertainty, the optimal strategy is to invest in one technology. This is solar or wind, depending on the combination of their initial costs and learning rates. This result goes against a lot of literature which suggests that diversity is preferable because of uncertainty and keeping options open, which is consistent also with the practice in most countries. This may go against intuition. The explanation for this result is perhaps that although there is uncertainty about prices or costs in our model setting, this is a case of traditional risk, that is, parameterized uncertainty. If, on the other hand, we would conceptualize the uncertainty as deep and pervasive or undefined (Knightian), diversifying would likely come out as a more desirable if not best strategy. Arguably, this is closer to the reality of renewable energy investment: it is difficult to assign credible probabilities about price variation and learning. This case, however, cannot be addressed with the method of real options but requires a different approach.

Finally, certain motivations for diversifying are possibly not or insufficiently covered by our model. This suggests a need for further research employing more complex models that include such motivations. An important one is keeping all significant technological options open so as to remain flexible in the face of unforeseen technological scenarios and undesirable environmental or social consequences of particular renewable energy technologies. Another is associated with the multidimensional nature of diversity, comprising variety (number of distinct types in a population), balance (distribution of types), and disparity (a measure of distance between the types) (Stirling, 2007; van den Bergh, 2008). Such dimensions can be best explored in a setting of many (i.e. more than two) options.

\section{Acknowledgements}

Financial support was given by the EU through the WWWforEurope project (www.foreurope.eu). 


\section{References}

Amram, M., Kulatilaka, N. 1999. Real Options: Managing Strategic Investment in an Uncertain World, Harvard Business School Press, Boston, MA.

Ashuri, B., Kashani, H. 2011. A real options approach to evaluating investment in solar ready buildings. In: Proceedings of congress on computing in civil engineering. Florida.

Biondi, T., Moretto, M. 2015 Solar Grid Parity dynamics in Italy: A real option approach. Energy, 80: 293-302.

Brealey, R.A., Mayers, S.C. 2003. Principles of Corporate Finance, seventh edition, The McGraw-Hill Series in Finance.

Brennan, M. J., Schwartz, E.S. 1985. "Evaluating natural resource investments," Journal of Business, 58(2), 135-157.

Bockman, T, Fleten, SE, Juliussen, E, Langhammer, HJ, Revdal, I. 2008. Investment timing and optimal capacity choice for small hydropower projects. European Journal of Operational Research. 190: 255-267.

Chen, Y.F., Funke, M. 2015. Going offshore: Investments in German wind energy under uncertainty. Cesifo working paper n. 5408. Available at:

http://papers.ssrn.com/sol3/papers.cfm?abstract id=2627070. Cited 17.11.2015.

Cheng, H., Hou, Y., Wu, F. 2010. Wind power investment in thermal system and emissions reduction. In: Proceedings of IEEE power and energy society general meeting. Minneapolis.

De Oliviera, D.L., Brandao, L.E., Igrejas, R., Lima Gomez, L. 2014. Switching outputs in a bioenergy cogeneration project: A real options approach. Renewable and Sustainable Energy Reviews. 36: 74-82.

Di Corato, L., Gazheli, A., Lagerqvist, C.J. 2013. Investing in energy forestry under uncertainty. Forest Policy and Economics. 34: 56-64.

Dixit, A.K., Pindyck, R.S. 1994. Investment under uncertainty, Princeton University Press, Princeton, NJ.

Dykes, K., de Neufville, R. 2008. Real options for a wind farm in Wapakoneta, Ohio: incorporating uncertainty into economic feasibility studies for community wind. World Wind Energy Conference. Ontario.

Ekern, S. 1988. An option pricing approach to evaluating petroleum projects. Energy Economics, 10: 91-99.

Felder, F.A. 1996. Integrating financial theory and methods in electricity resource planning. Energy Policy, 24: 149-54.

Fleten, S.E, Maribu, K.M. 2004. Investment timing and capacity choice for small scale wind power under uncertainty. Series on Energy and Power Systems 121-6.

Gazheli, A., Di Corato, L. 2013. Land-use change and solar energy production: a real option approach. Agricultural Finance Review, 73(3): 507-525.

Ghosh, K., Ramesh, V.C. 1997. An options model for electric power markets. International Journal of Electrical Power \& Energy Systems, 19:75-85.

Hedman, K.W., Sheble, G.B. 2006. Comparing hedging methods for wind power: using pumped storage hydro units vs. options purchasing. In: International conference on probabilistic methods applied to power systems. Sweden.

Hoff, T.E., Margolis, R., Herig, C. 2003. A simple method for consumers to address uncertainty when purchasing photovoltaics. Cleanpower research [online]. Available from: http://www.cleanpower.com/Research.

Jeon, C., Lee, J., Shin, J. 2015. Optimal subsidy estimation method using system dynamics and the real option model: Photovoltaic technology case. Applied Energy, 142: 33-43.

Lin, B., Wasseh, P.K.Jr. 2013. Valuing Chinese feed-in tariffs program for solar power generation: A real options analysis. Renewable and Sustainable Energy Reviews. 28: 474482. 
Kjaerland, F. 2007. A real option analysis of investments in hydropower - The case of Norway. Energy Policy, 35: 5901-5908.

Kjaerland, F., Larsen, B. 2009. The value of operational flexibility by adding thermal to hydropower a real option approach. In: 9th annual real options international conference. Portugal and Spain.

Kim, K.T., Lee, D.J., Park, S.J. 2014. Evaluation of R\&D investments in wind power in Korea using real option. Renewable and Sustainable Energy Reviews, 40: 334-347.

Kimbaroglu, G., Madlener, R., Demirel, M. 2008. A real options evaluation model for the diffusion prospects of new renewable power generation technologies.

Kroniger, D., Madlener, R. 2014. Hydrogen storage for wind parks: A real options evaluation for an optimal investment in more flexibility. Applied Energy, 136: 931-946.

Majd, S., Pindyck, R.S, 1989. The learning curve and optimal production under uncertainty. RAND Economic Journal 20: 331-343.

Martinez-Cesena, E.A., Mutale, J. 2011. Application of an advanced real option approach for renewable energy generation projects planning. Renewable and Sustainable Energy Reviews, 15: 2087-94.

Martinez-Cesena, E.A., Mutale, J. 2011. Assessment of demand response value in photovoltaic systems based on real options theory. In: Proceedings of IEEE PowerTech. Norway.

Martinez-Cesena, E.A., Mutale, J. 2012. Wind power projects planning considering real options for the wind resource assessment. IEEE Transactions on Sustainable Energy, 3:158-66.

Martinez-Cesena, E.A., Mutale, J., Rivas-Davlos, F. 2013. Real options theory applied to electricity generation projects: A review. Renewable and sustainable Energy Reviews, 19: 573-581.

Martinez-Cesena, E.A., Azzopardi, B., Mutale, J. 2012. Assessment of domestic photovoltaic systems based on real options theory. Progress in Photovoltaics: Research and Applications [online]. Available from:/http://onlinelibrary.wiley.com/doi/10.1002/pip.2208/pdf.

Mendez, M., Goyanes, A., Lamothe, P. 2009. Real options valuation of a wind farm. In: 9th annual real options international conference. Portugal and Spain.

Menegaki, A., 2008. Valuation for renewable energy: a comparative review Renewable and Sustainable Energy Reviews, 12 pp. 2422-2437.

Monjas Barroso, M., Balibrea Iniesta, J. 2014. A valuation of wind power projects in Germany using real regulatory options, Energy, 77: 422-433.

Muñoz, J.I., Contreras, J., Caamaño, J., Correia, P.F. 2009. Risk assessment of wind power generation project investments based on real options IEEE Bucharest power tech. Available at: http://ieeexplore.ieee.org/stamp/stamp.jsp?tp=\&arnumber=5281848. Cited on 05.02.2015.

Paddock, J.L., Siegel, D.R., Smith, J.L., 1988. Options valuations of claims on real assets: The case of offshore petroleum leases. The Quaterly Journal of Economics, 103: 479-508.

Santos, L., Soares, I., Mendes, C., Ferreira, P. 2014. Real Options versus Traditional Methods to assess Renewable Energy Projects. Renewable Energy, 68: 588-594.

Sarkis, J., Tamarkin, M. 2008. Real options analysis for renewable technologies in a GHG emissions trading environment. Emissions Trading, 109-119.

Scatasta, S., Mennel, T. 2009. Comparing feed-in-tariffs and renewable obligation certificates the case of - wind farming. In: 9th annual real options international conference. Portugal and Spain.

Shemelev, S., and J. van den Bergh (2016). Optimal diversity of renewable energy alternatives under multiple criteria: An application to the UK. Renewable and Sustainable Energy Reviews 60: 679-691.

Siddiqui, A., Fleten, S.E. 2010. How to proceed with competing alternative energy technologies: A real options analysis. Energy Economics. Article in press. 
Siegel, D.R., Smith J.L., Paddock J.L. 1987. Valuing offshore oil properties with option pricing models. Midland Corporate Finance Journal, 22-30.

Skea, J. (2010). Valuing diversity in energy supply. Energy Policy 38: 3608-3621.

Stirling, A. (2007). A general framework for analysing diversity in science, technology and society. Journal of the Royal Society Interface 4(15): 707-719.

Stirling, A. (2010). Multicriteria diversity analysis: a novel heuristic framework for appraising energy portfolios. Energy Policy 38: 1622-1634.Tourinho, O.A.F. 1979. The valuation of reserves of natural resources: an option pricing approach: University of California, Berkeley.

Trigeorgis, L. 1996. Real Options: Managerial Flexibility and Strategy in Resource Allocation. The MIT Press, Cambridge, MA.

van den Bergh, J.C.J.M. (2008a). Optimal diversity: Increasing returns versus recombinant innovation. Journal of Economic Behavior and Organization 68(3-4): 565-580.

van den Bergh, J., 2010. Safe climate policy is affordable -12 reasons. Climate Change, 101: 339-385.

van den Heuvel S.T.A., van den Bergh J.C.J.M. (2009). Multilevel assessment of diversity, innovation and selection in the solar photovoltaic industry. Structural Change and Economic Dynamics 20(1): 50-60.Wang, T. 2005. Real options in projects and systems designs: identification of options and solution for path dependency. PhD dissertation. Massachusetts: Massachusetts Institute of Technology.

Wang, T., de Neufville R. 2004. Building real options into physical systems with stochastic mixed-integer programming. In: 8th annual real options international conference. Canada.

Wang, T., de Neufville R. 2006. Identification of real options in projects. In: $4^{\text {th }}$ annual conference on systems engineering research. California.

Wasseh, P.K., Boqiang, L.Jr. 2015. Renewable energy technologies as beacon of cleaner production: a real options valuation analysis for Liberia, Journal of Cleaner Production, 90: 300-310.

Yu, W., Sheble, G.B., Pecas Lopez, J.A., Matos, M.A. 2006. Valuation of switchable tariff for wind energy. Electric Power Systems Research, 76: 382-388.

Zhang, X., Wang, X., Wang, X., Chen, H. 2005. Energy uncertainty risk management of hydropower generators. Transmission and distribution conference and exhibition: Asia and Pacific. China.

Zhang, M., Zhou, D, Zhou, P. 2014. A real option model for renewable energy policy evaluation with application to solar PV power generation in China. Renewable and Sustainable Energy Reviews, 40: 944-955.

Zhou, H., Hou, Y., Wu, Y., Yi, H., Mao, C., Chen, G. 2007. Analytical assessment of wind power generation asset in restructured electricity industry. United Kingdom: Universities Power Engineering Conference. 